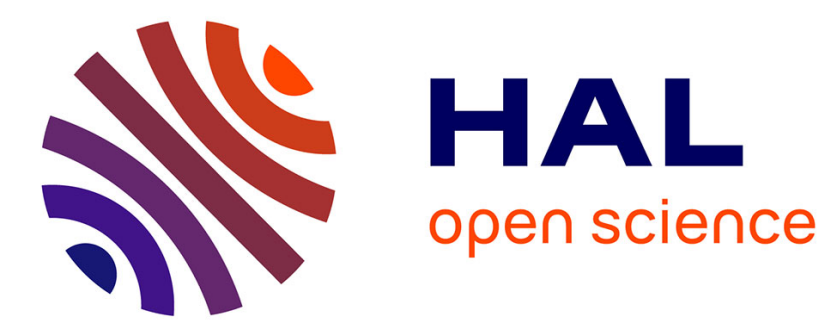

\title{
Integration of PV systems into grid: From impact analysis to solutions \\ Tuan Tran Quoc
}

\section{To cite this version:}

Tuan Tran Quoc. Integration of PV systems into grid: From impact analysis to solutions. 2018 IEEE International Conference on Environment and Electrical Engineering and 2018 IEEE Industrial and Commercial Power Systems Europe (EEEIC / I\&CPS Europe), Jun 2018, Palermo, Italy. cea03249352

\section{HAL Id: cea-03249352 https://hal-cea.archives-ouvertes.fr/cea-03249352}

Submitted on 4 Jun 2021

HAL is a multi-disciplinary open access archive for the deposit and dissemination of scientific research documents, whether they are published or not. The documents may come from teaching and research institutions in France or abroad, or from public or private research centers.
L'archive ouverte pluridisciplinaire HAL, est destinée au dépôt et à la diffusion de documents scientifiques de niveau recherche, publiés ou non, émanant des établissements d'enseignement et de recherche français ou étrangers, des laboratoires publics ou privés. 


\title{
Integration of PV Systems into Grid: From Impact Analysis to Solutions
}

\author{
Quoc-Tuan Tran, Senior Member IEEE, M. Cong Pham, L. Parent, K. Sousa \\ CEA - National Institute for Solar Energy (CEA-INES) \\ 50 Avenue du Lac Léman, \\ 73377 Le Bourget-du-Lac, France \\ QuocTuan.Tran@cea.fr
}

\begin{abstract}
The integration PV systems into grid, due to the intermittent characteristics, can have several impacts on the network functionalities such as the stability, the protection and introduces new management and planning challenges. Theses impacts are more complicated for an islanded grid or weak grid. A better knowledge of the induced constraints becomes necessary in order to determine the PV penetration level, to assess impacts of PV generation on distribution network and to assess technical and economic opportunities provided by PV generation. This paper presents analyses on the impacts of PV systems integration to the grid: variation of voltage and frequency, voltage unbalance, etc. Several solutions, based on intelligent control, protection and energy storage in order to reduce these impacts, to maximize the ancillary services contributed by PV systems and to maintain the grid stability are proposed.
\end{abstract}

Keywords-PV system, Impact analysis, voltage control, unbalance, stability, grid.

\section{INTRODUCTION}

In the context of the energy transition (in France, the objective is reaching $40 \%$ of renewable energy in 2030 , with $50 \%$ of renewable energy by 2020 in the DOM/TOM departments), the integration of renewable energy resources (RES) in power grids will be mainly limited by technical constraints and the problem of frequency instabilities caused by intermittency and low inertia of RES. Photovoltaic (PV) is a sustainable energy source and the worldwide growth of photovoltaic is extremely dynamic and varies strongly by country [1]. The connection of solar PV system to the grid, with intermittent characteristic, can raise several technical problems or can have significant impacts on power systems such as:

- Changing the voltage profile

- Varying the power production

- Increasing the voltage unbalance between phases

- Increasing harmonics on the network

- Introducing stability and protection problem: with great number of PV inverters connected to grid, the inertia of network is low and the short-circuit currents are small, etc.

The connection of PV system to the grid must respect standards or grid codes [3-9]. Therefore a better knowledge of the induced constraints is necessary in order to determine the PV penetration level, to identify PV integration challenges. In this paper, we consider the impact of PV system to the power

978-1-5386-5186-5/18/\$31.00 C2018 IEEE system and the methods of assessment for such impacts on distribution network. Several innovative solutions are presented to address the aforementioned problems and to assess the opportunities provided by PV generation. Simulations are carried out on different grids to evaluate the proposed solutions.

The paper is organized as following: in section II. we recall the concept of microgrid as the novel structure for integration of RES or PV systems to the electrical grid. In section III. the tools for impact assessment of the integration of PV to the grid is presented and illustrated on a rural MV network with PV installations. In section IV. an adaptive voltage control based on fuzzy logic is presented to reduce the impact of the intermittency of PV. Section V. proposes a new control strategy with three-phase PV inverter to reduce voltage unbalance rate when connecting PV systems to the LV distribution network. Fault-Ride-Through (FRT) control is proposed in section VI. to improve the stability of the microgrid in islanded mode. Association of PV production with energy storage is considered in section VII. before the proposed solutions are summarized and the contribution is concluded in section VIII.

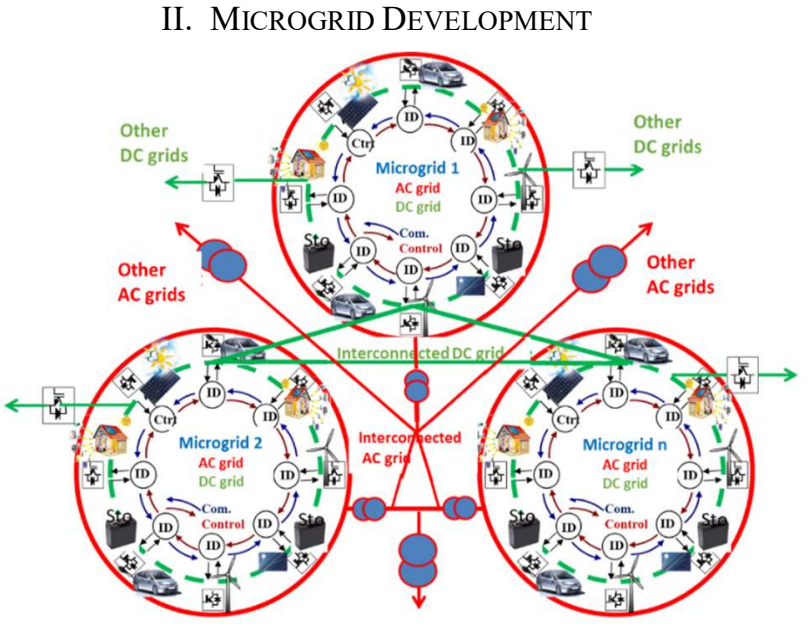

Fig. 1. Scheme of microgrid defined in PARADISE Project [2].

Microgrids, as the fundamental "building block of smart grid", are probably the most promising novel structure of grids. A microgrid concept is a good solution in order to integrate renewable energy sources (RES) or PV systems in the electrical grid. A microgrid is a group of interconnected loads and distributed energy resources (DER) with clearly entity with respect to the grid. It can operate in both grid-connected or 
island mode. A scheme of the microgrids defined in the PARADISE project is shown in Fig. 1 [2].

The integration of RES into a microgrid can cause negative impacts on microgrid functionality. It is therefore necessary to develop new strategies of control and management for microgrid. Various projects have been carried out in an effort to alleviate these challenges [2, 12-17].

\section{IMPACT ASSESSMENT OF PV INTEGRATION INTO GRIDS}

To address the intermittency of PV production and loads and its impacts on the distribution network, a probabilistic three phase Load Flow (PLF) is developed based on Monte Carlo techniques (Fig. 2). Two modes of simulation can be realized:

- Deterministic simulation with fixed parameters

- Monte-Carlo simulation with some parameters defined as random variables such as loads, PV production, etc.

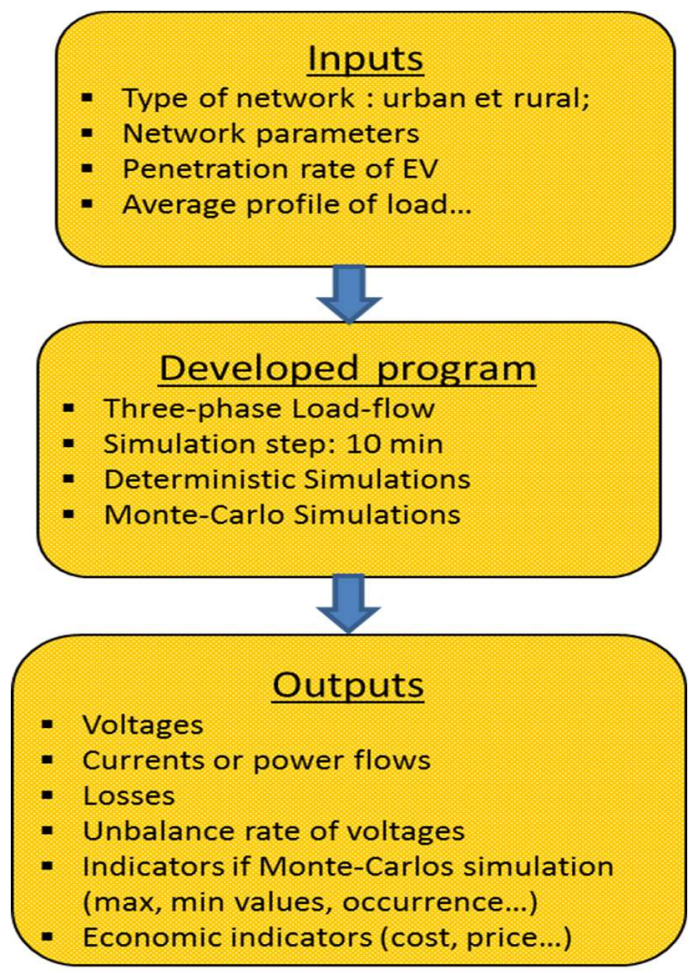

Fig. 2. Description of the methodology

After identifying the critical cases by using the developed tool, solutions can be developed and re-evaluated in particular to avoid the congestion, to maintain voltage within limits.

The proposed tool allows determining the maximal penetration rate of PV systems into grid, with respect to the constraints of voltages and power flows.

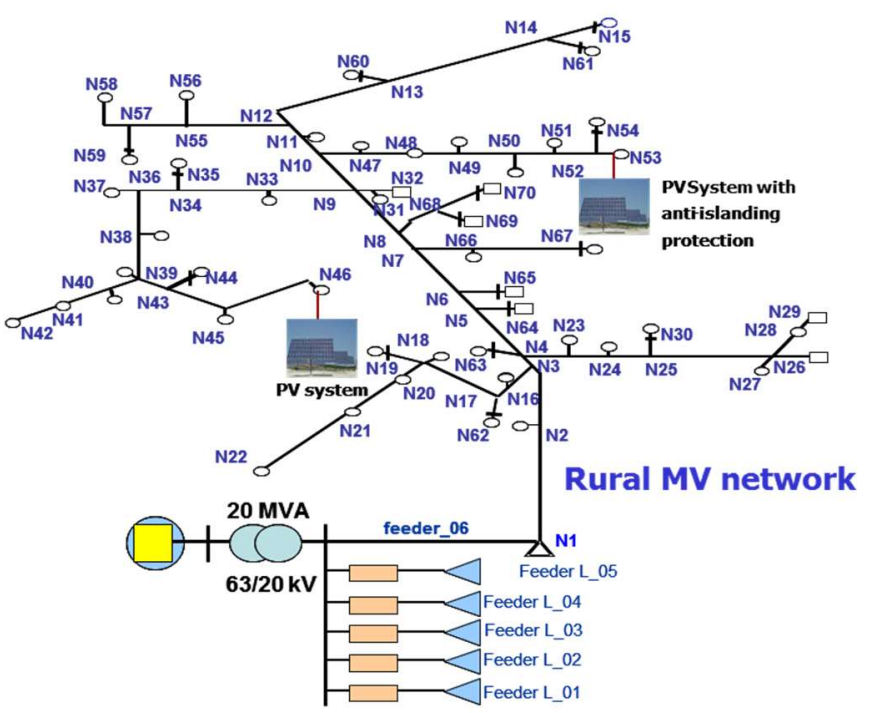

Fig. 3. Distribution network with PV installations

To demonstrate the performance of the proposed technique, a MV distribution network with PV installations is used as shown in Fig. 3. We present and analyze here the determination of the maximal capacity of PV systems connected to grid in three cases:

Case 1: With a PV system installed at bus 53, the maximal capacity of PV system is $6.85 \mathrm{MW}$. For this case, the connection capacity is limited by the overload constrains. There are overloads on certain lines (Critical lines: 10-47, 47-48, 48-49, 49-50, 50-51, 51-52) and no voltage variation (Fig. 4).

Case 2: With PV systems installed at bus 53 and 61, the maximal capacity of PV system is $13.09 \mathrm{MW}$ (S_PV_53=6.78 MW, S_PV_61=6.31 MW). For this case, the connection capacity is limited by the voltage constrains. There are voltage violations at buses: 14, 15, 52-54, 61 and no overload (Fig. 5).

Case 3: With a PV system installed at bus 53, 36, 58, the maximal capacity of PV system is $14.67 \mathrm{MW}$ (P_PV_36=6.51 MW, P PV 53=1.31 MW, P PV 58=6.85 MW). For this case, the connection capacity is limited by the overload constrains. There are overloads on lines 9-33, 33-34, 34-36, 12-55, 55-57, 57-58 (Fig. 6).
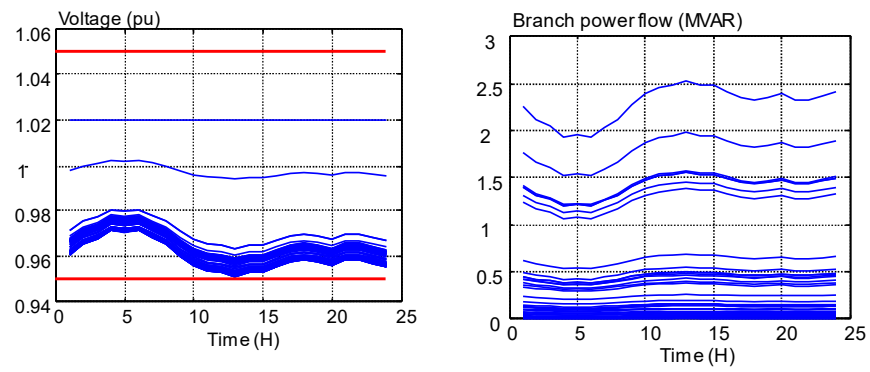

Fig. 4. Voltage variation and power flow in lines 

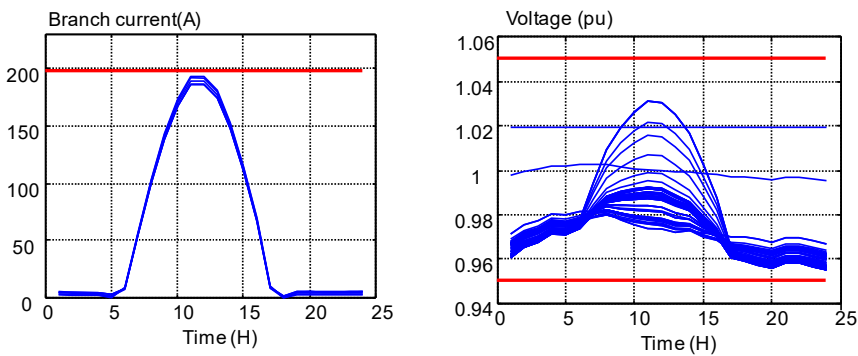

Fig. 5. a: Congestion; $\mathrm{b}$ : no voltage violation $\left(\mathrm{P}_{\max }=6.85 \mathrm{MW}\right)$
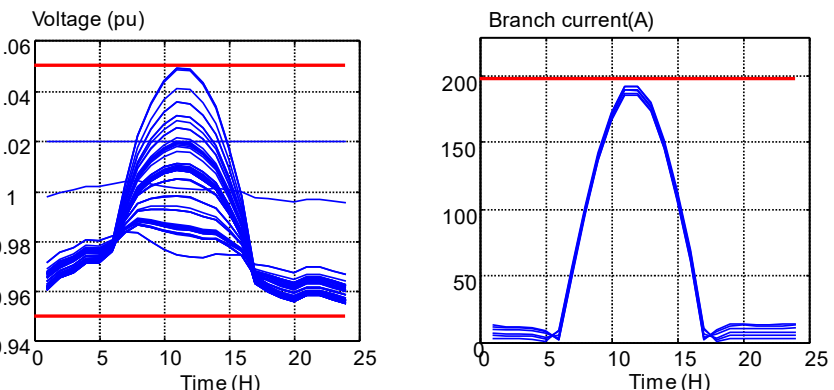

Fig. 6. a: Case 2: Voltage violation (Pmax=13.09 MW); b-Case 3: Over load $(\mathrm{Pmax}=14.67 \mathrm{MW})$;

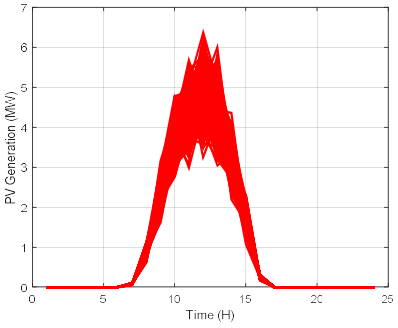

Fig. 7. Random variation of PV production

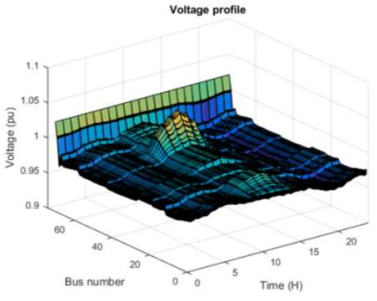

Fig. 9. Voltage variation with a random variation of $\mathrm{PV}$ at bus 53 (Case 1)

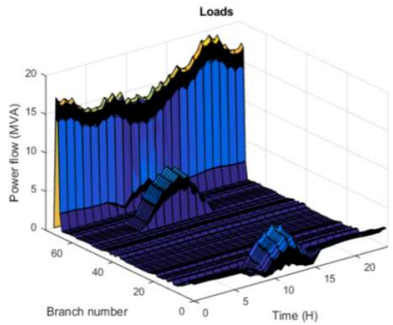

Fig. 8. Power flow on branches

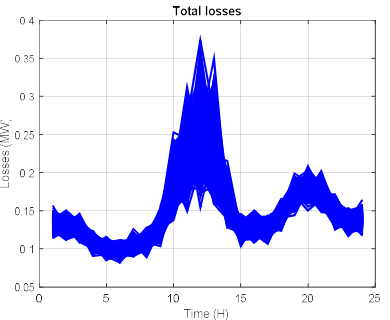

Fig. 10. Losse variation with a random variation of $\mathrm{PV}$ at bus 53 (Case 1)
Using Monte-Carlo simulation with random variables of load and PV generation (Fig. 7 for PV generation variation), the variation of power flow on the transformer and all lines (Fig. 8), the voltage variation (Fig. 9) and loss variation (3) of network are observed. For theses simulations, there are no problem for congestion or voltage violation because the PV productions are inferior to $6.85 \mathrm{MW}$ (maximal limit).

\section{ADAPTIVE VOLTAGE CONTROL}

The connection of PV systems may cause voltage fluctuation in the network. With $\mathrm{P} / \mathrm{Q}$ classic control (reactive powers equal to zero), there are overvoltages (superior to $1.1 \mathrm{pu}$ (LV) or $1.05 \mathrm{pu}(\mathrm{MV})$ ) in case of strong irradiation and light load and undervoltages (inferior to $0.9 \mathrm{pu}(\mathrm{LV})$ or $0.95 \mathrm{pu}$ $(\mathrm{MV}))$ in case of heavy load and no sun. In these scenarios, the
PV systems may be disconnected by protection system. This frequent disconnection of PV inverters can reduce their lifetime and perturb the network operation and is therefore unwanted.

An auto-adaptive voltage control based on fuzzy logic is proposed to partly respond to this problem with not only technical but also economical advantages: local decisions are based only on local measures. This avoids investments on communication systems for DNOs. Fig. 11 and Fig. 12describes the working principle of adaptive voltage control.

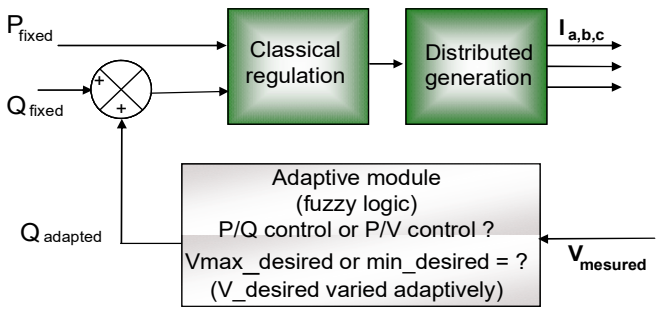

Fig. 11. Principe of adaptive control

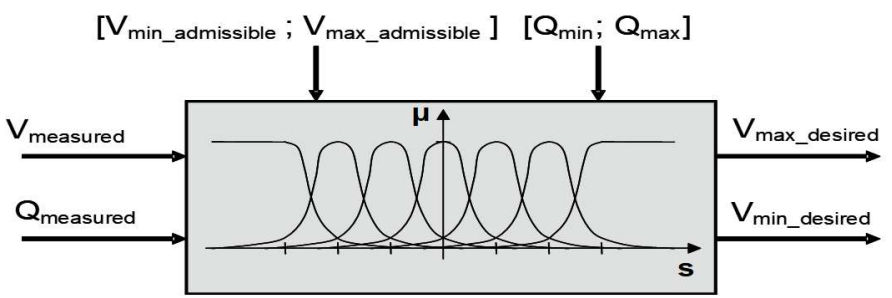

Fig. 12. Determination of voltage setpoint by fuzzy logic

To demonstrate this adaptive control, we consider a typical MV rural network powered by a transformer 20 MVA, $63 / 20 \mathrm{kV}$. Three PV power systems are connected in this network (Fig. 13).

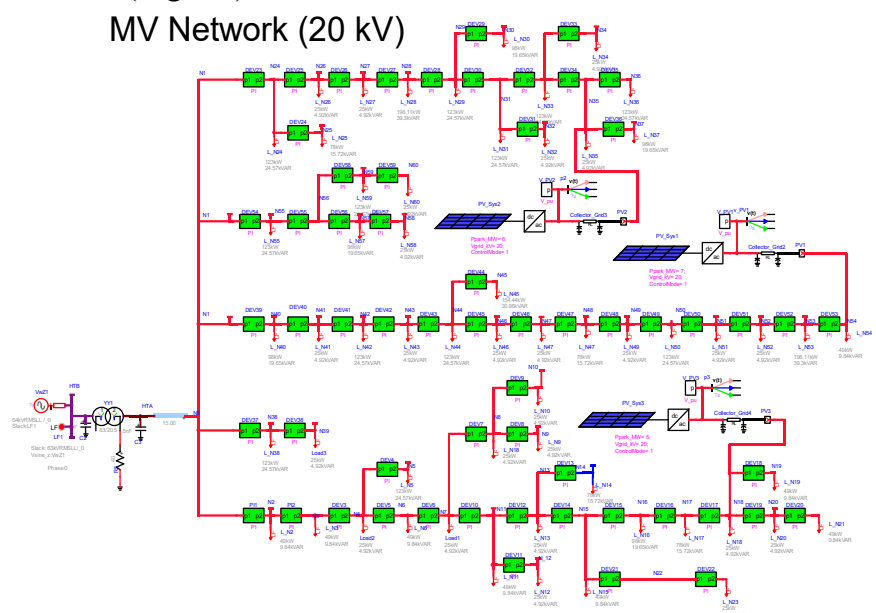

Fig. 13. MV distribution network with three PV power systems

With P/Q classic control, there are overvoltages superior to $1.05 \mathrm{pu}$ in case of strong irradiation and light load and undervoltages inferior to $0.95 \mathrm{pu}$ in case of heavy load and no sun. Fig. 14 shows the active and reactive power variation of PV systems with the P/Q control. Fig. 15 shows the voltage variation of PV systems for this case (overvoltage). 


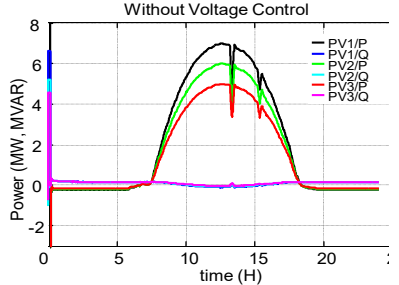

Fig. 14. Power variation of $P V$ systems with the $\mathrm{P} / \mathrm{Q}$ control

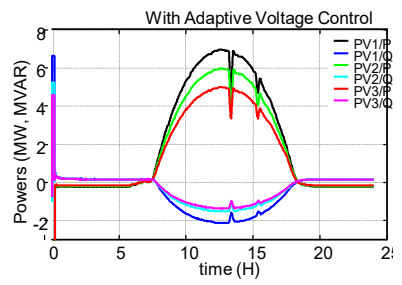

Fig. 16. Power variation of $\mathrm{PV}$ systems with the proposed control

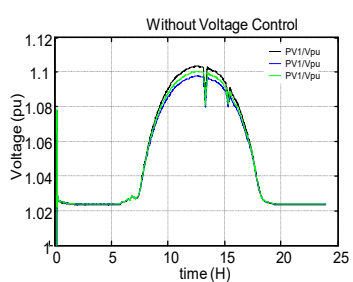

Fig. 15. Voltage variation of PV systems with the $\mathrm{P} / \mathrm{Q}$ control

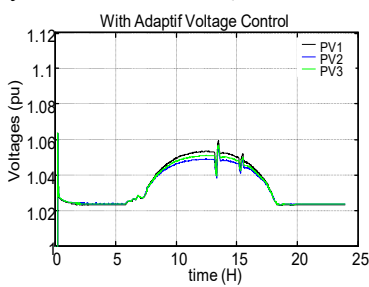

Fig. 17. Voltage variation of PV systems with the proposed control

With the proposed adaptive voltage control solution, all PV systems participate to locally control voltage without communication. They can absorb reactive power to reduce overvoltages (Fig. 16). During the peak load, PV systems provide reactive power to maintain a high level of voltage in order to reduce losses (Fig. 16). Fig. 17 shows the voltage variation for all nodes in the network. For this solution, all voltages are maintained in admissible limits.

\section{Reducing Voltage Unbalance Rate with novel CONTROL STRATEGY FOR THREE-PHASE PV INVERTER}

The majority of PV systems connected to LV networks are generally in single phase inverters. The distribution of these inverters on the three phases of the network is not homogenous. The distribution of single-phase loads on the three phases of the network is also homogeneous. This can cause significant voltage unbalances between the three phases.

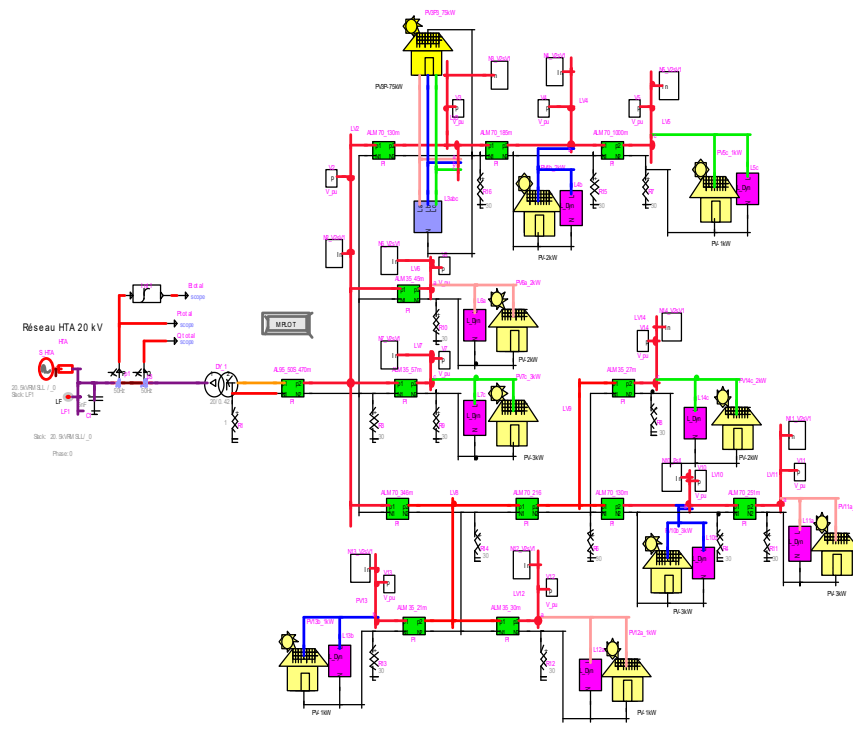

Fig. 18. LV distributed network with PV systems

Indeed, a LV distribution network may present (e.g. Fig. 18), under certain conditions, situations of unbalance between phases generated by the single-phase loads. This unbalance of

the voltage between the phases of a network results in the appearance of a current in the neutral of the network. This can generate overheating of rotating machines (by reverse current) and additional losses.

To cope with this phenomenon, a new control is proposed to permit the reduction of the rate of voltage unbalance of the network by using the services provided by a three-phase PV inverter. Significant imbalances of voltage can be seen that during periods of strong irradiation (from 8 to 18 hours). The unbalance rate can exceed $2 \%$ with $\mathrm{P} / \mathrm{Q}$ control. With intelligent control, the unbalance rate is reduced to less than $1 \%$. Fig. 19 shows the voltage unbalance at bus 3 with intelligent control over P/Q control.

The obtained results show the performance of the proposed solution in reducing the voltage unbalance rate. For singlephase loads (total of $33.6 \mathrm{~kW}$ and $12.2 \mathrm{kVAR}$ ), using the proposed method, $1.6 \mathrm{kWh}$ per day, or $584 \mathrm{kWh}$ per year of losses can be reduced.
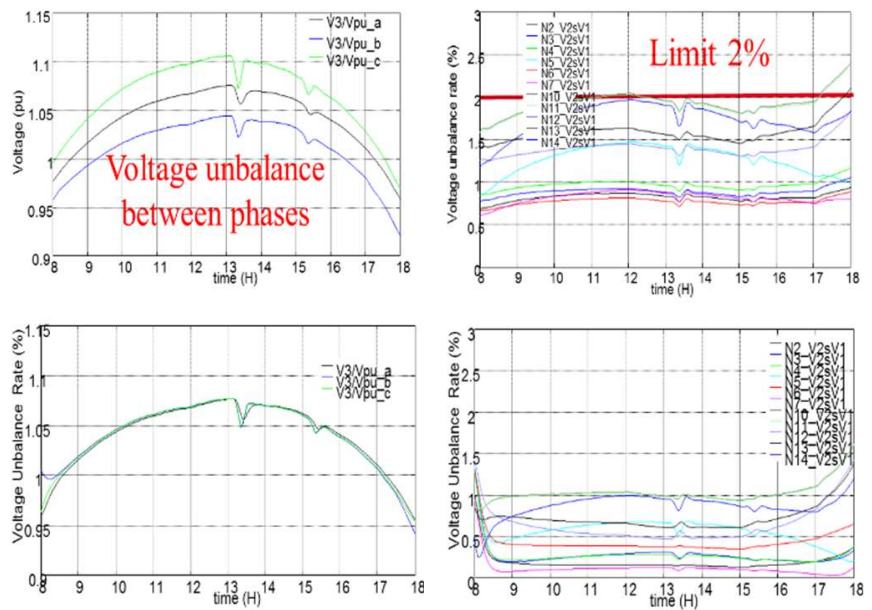

Fig. 19. Voltage unbalance without and with intelligent control

The proposed method allows the reduction of:

- the voltage inverse component, thus reducing the voltage unbalance rate among the three phases,

- the current flowing in the neutral,

- Additional losses on the network.

\section{FAULT-RIDE-THROUGH CONTROL CAPABILITY IN STABILITY OF AN ISLAND NETWORK}

The high penetration of photovoltaic (PV) into an isolated grid may cause the stability problem. In case of short-circuit or voltage sag, PV systems with a classic protection (based on limits of voltage and frequency) may be disconnected from network. The loss of an important quantity of PV systems in this network may lead to perturbations and instability of angular, frequency and voltage. In order to avoid the instability, the solutions of using Fault Ride Through (FRT) control strategy is proposed for all PV inverters.

The proposed solution is investigated in framework of smart grid in Guadeloupe Island, France (Fig. 20). 


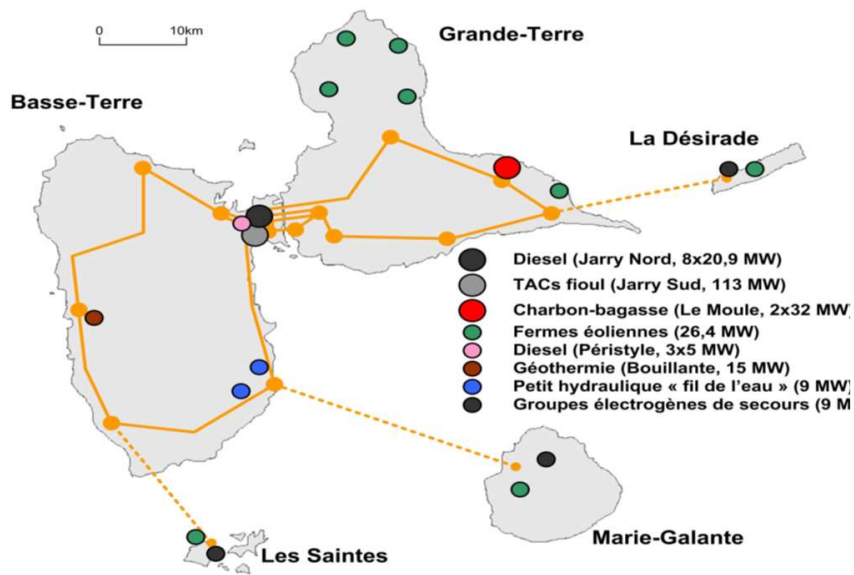

Fig. 20. Isolated grid of Guadeloupe

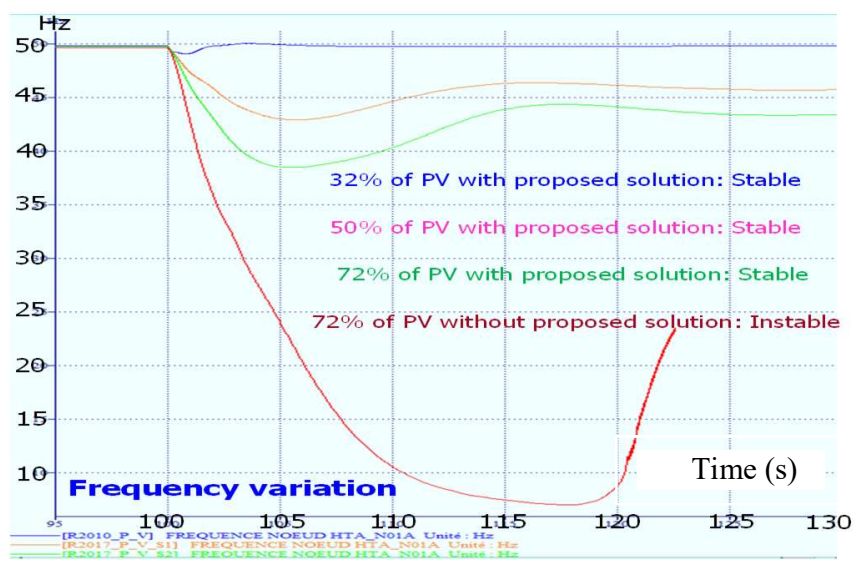

Fig. 21. Frequency variation for 3, 32, 50 and $72 \%$ of PV penetration with proposed solutions

Fig. 21 shows the frequency variations in Guadeloupe with the penetration rate of $\mathrm{PV}$ about 2, 32, 50 and $72 \%$, respectively. Short-circuit occurs at $\mathrm{t}=100 \mathrm{~ms}$ (with $200 \mathrm{~ms}$ duration) with and without FRT control strategy (i.e classical protection). Without FRT solution (i.e. classical protection) this grid is unstable and the maximal penetration rate of $\mathrm{PV}$ in this grid is limited about $30 \%$.

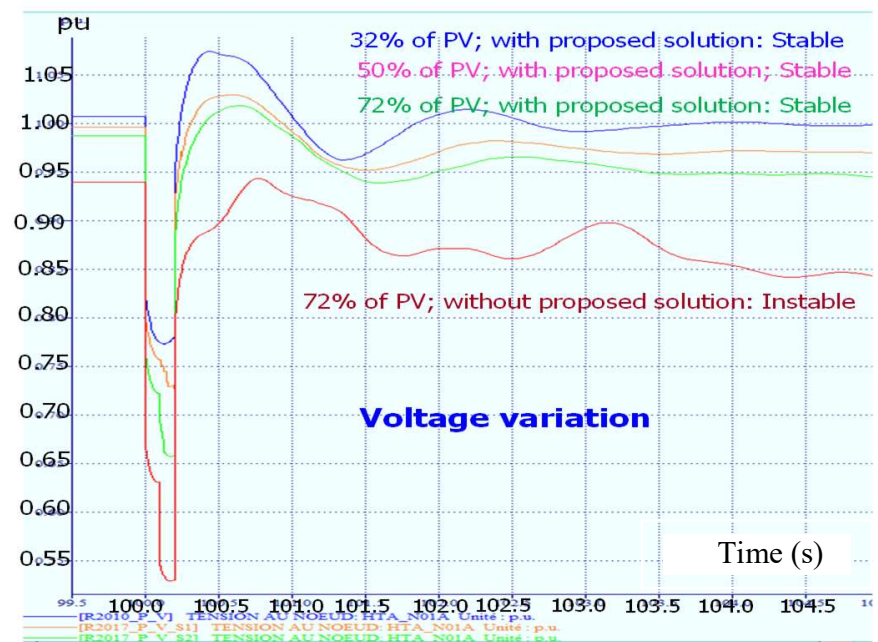

Fig. 22. Voltage variation for 3, 32, 50 and $72 \%$ of PV penetration without and with proposed solutions

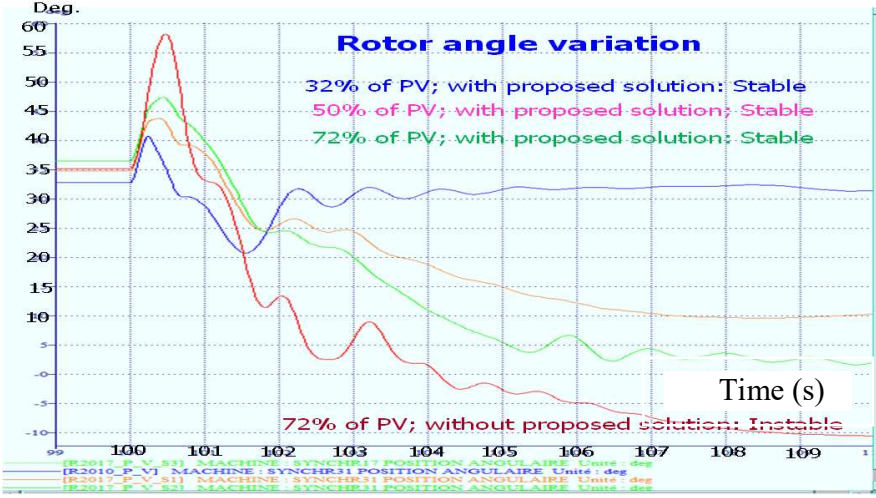

Fig. 23. Rotor angle variation for 3, 32, 50 and $72 \%$ of PV penetration without and with proposed solutions

With the proposed solutions using Fault Ride Through, this grid is always stable for different penetration rates, even with $72 \%$ of PV (Fig. 21 to Fig. 23). In general, this innovative solution allows us to increase the penetration rate of $\mathrm{PV}$.

\section{Photovoltaic Production Assosiated With STORAGE SOLUTIONS}

In a context where renewable energies from both wind and solar origin have low predictability, low controllability and strong variability, their massive integration into power systems may cause instabilities for these grids. Utilization of storage energy systems is a promising solution for solving such problems. However, high capital investment cost for batteries constitutes a major obstacle to the widespread deployment of battery energy storage systems as a tool to support the integration of renewable energy sources (RES) into the electricity grid. The availability of storage at a competitive and large-scale cost will therefore be a key factor in responding to the increasing penetration of renewable energies and the variability of demand.

In this section, we consider the benefit of association of flywheel energy storage system (FESS) and Battery Energy Storage System (BESS) to photovoltaic power generation (PV) $[12,16]$.
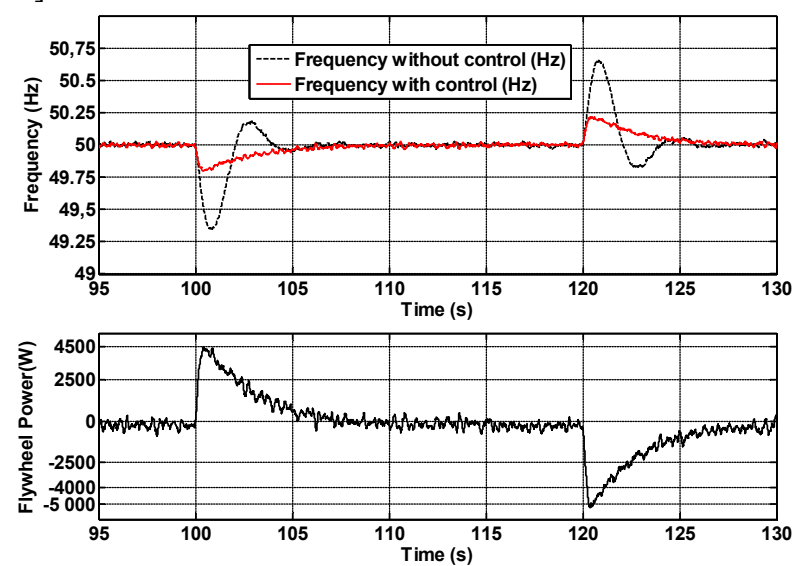

Fig. 24. Frequency variation with and without frequency control (a) and Flywheel Power (b) in case of change of PV production

For this purpose, an islanded grid is simulated by real time simulator in order to test its ability for grid ancillary service: voltage, frequency regulation and PV power smoothing. The 
FESS is then connected to the grid. According to the inertia of the grid, the flywheel system is more or less able to smooth the frequency, the voltage and the PV production. Fig. 24 shows the frequency variation with and without FESS and FESS power output.

Another solution in consideration is battery energy storage system (BESS) associated to photovoltaic power generation (PV) [14-17]. Fig. 25 shows one-day production schedule of two ESSs and a PV power plant in a Virtual Power Plant, with net market bids in the day-ahead energy (Market) and tertiary reserve market (Res) (Top: current German market rules, bottom: quarter-hourly energy market contracts and relaxed minimal reserve amount constraint).

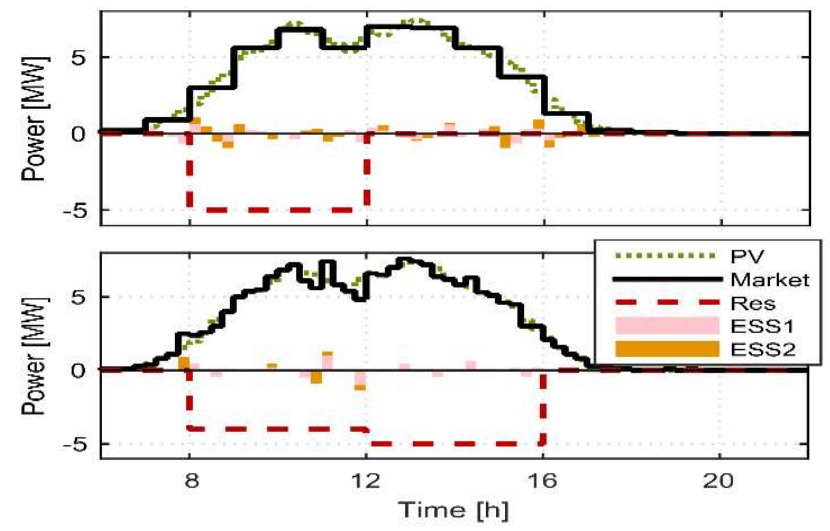

Fig. 25. One-day production schedule of two ESSs and a PV power plant in a Virtual Power Plant

The optimization of the dispatch schedules has been employed in the past to aid the sizing of BESS and to drive down capital expenditures by limiting the installed battery capacity to the minimum required for the application. An optimized operation strategy is used to reduce replacement costs for the batteries by adapting the state-of-charge and power solicitation to achieve minimized lifetime. To this end, a simplified model for both calendar and cycle aging of Li-ion batteries is integrated into a mixed-integer linear programming algorithm. In [17] an adaptive identification of BESS model with online self-adapting capability has been developed. The developed model is used to investigate different strategies of control and energy management.

BESSs are already operated in commercial MW-scaled photovoltaic (PV) installations to facilitate power production levelling and participation in auxiliary services, such as frequency and voltage control.

In general, several challenges for energy storage deployment and implication into the power system are:

- What are the most promising technologies?

- What services can make storage in the electrical system?

- How to remove the regulatory and economic obstacles to the deployment of storage?

- What will be the economic model of electricity storage?

\section{CONCLUSION}

The integration PV systems into grid, due to the intermittent characteristics, can have several impacts on the network functionalities such as the stability, the protection and introduces new management and planning challenges. Therefore, this paper has proposed several studies on the subject of impact assessment of PV integration into grid, voltage control of PV systems, reducing voltage unbalance, stability of an islanded grid with high penetration of PV systems and energy storage solutions. Simulations have been carried out with different scenarios in order to evaluate the performance of the proposed solutions. This paper has shown that for a high penetration of PV integration into grid, it's necessary to study, propose and coordinate the different strategies of control, management and protection in order to maintain a good operation of the grid.

\section{Acknowledgement}

This work is supported by the European Community's Horizon 2020 Framework Programme under the project UNITED GRID (grant agreement 773717)

\section{REFERENCES}

[1] https://en.wikipedia.org/wiki/Solar_power_by_country

[2] PARADISE (ANR ${ }^{2}$ Project ID: ANR-13-PRGE-0007): high penetration of renewable energy resources into grid with distributed storage systems

[3] DIN VDE 0126-1-1, "Automatic disconnection device between a generator and the public low-voltage grid", Fev. 2006

[4] IEEE Std 929-2000, "IEEE Recommended Practice for Utility Interface of Photovoltaic (PV) Systems", April 2000

[5] UL 1741, "Inverter, converters, and controllers for use in independent power systems," 2002

[6] IEEE Std. 1547, "Standard for Interconnecting Distributed Resources with Electric Power Systems," 2003

[7] IEC Std. 62 116, "Test procedure of islanding prevention measures for utility-interconnected photovoltaic inverters", 2008.

[8] ERDF-NOI-RES_13E, "Protections des installations de production raccordées au réseau public de distribution Identification", 2013

[9] VDE-AR-N 4105, "Generators connected to the low-voltage distribution network"

[10] T. Tran-Quoc, C. Andrieu, N. Hadjsaid, "Technical impacts of small distributed generation units on LV networks", IEEE General Meeting 2003, Canada, June 2003

[11] T. Tran-Quoc, X. Le Pivert, J. Merten, "Analysis of Photovoltaic Generation Impacts on Distribution Networks"; Conférence PVSEC - The 27th European Photovoltaic Solar Energy Conference and Exhibition, 24 - 28th September 2012, Frankfurt (DE)

[12] Cédric Abbezzot, Tuan Tran Quoc, "Flywheel Energy Storage system used in a Photovoltaic Power Generation System", 3rd International Conference on Energy Process Engineering (ICEPE 2013), Franfurk, Germany, 4-6th june, 2013

[13] NA Luu, T. Tran-Quoc, "Optimal energy management for an island microgrid by using Dynamic programming method"; Conference IEEE/Powertech, 29th June - 2nd july 2015, Eindhoven, Holand

[14] E. Krüger and Q. T. Tran, "Minimal aging operating strategies for battery energy storage systems in photovoltaic applications,", IEEE-ISGT, Innovative Smart Grid Technologies Conference, 9-12 October 2016, Ljubljana, Slovenia

[15] Q. T. Tran, NA Luu, "Optimal Energy Management Strategies of Microgrids", The 2016 IEEE Symposium- Special Session: Intelligent Management of Micro Grids and Buildings (IEEE SSCI - CIASG 2016) - 6-9 december 2016 Athens, Geece.

[16] Cedric ABBEZZOT, "Flywheel energy storage system coupled to the photovoltaic generator and controlled by a real-time simulator"; $\mathrm{PhD}$ Thesis prepared at the CEA-INES, Defended on 15 December 2014

[17] Eiko KRUGER, "Development of algorithms for optimal management of energy storage systems based on adaptive models", $\mathrm{PhD}$ Thesis prepared at the CEA-INES, Defended on 21 November 2016. 